\title{
Review \\ Antimicrobial Resistance among Beta-Hemolytic Streptococcus in Brazil: An Overview
}

\author{
Rosana Rocha Barros (D)
}

check for

updates

Citation: Barros, R.R. Antimicrobial Resistance among Beta-Hemolytic Streptococcus in Brazil: An Overview. Antibiotics 2021, 10, 973. https:// doi.org/10.3390/antibiotics10080973

Academic Editor: Sauli Haataja

Received: 15 June 2021

Accepted: 10 August 2021

Published: 12 August 2021

Publisher's Note: MDPI stays neutral with regard to jurisdictional claims in published maps and institutional affiliations.

Copyright: (C) 2021 by the author. Licensee MDPI, Basel, Switzerland. This article is an open access article distributed under the terms and conditions of the Creative Commons Attribution (CC BY) license (https:// creativecommons.org/licenses/by/ $4.0 /)$.
Departamento de Microbiologia e Parasitologia, Instituto Biomédico, Universidade Federal Fluminense Niterói 24210-130, Brazil; rrbarros@id.uff.br

Abstract: Streptococcus pyogenes, Streptococcus agalactiae and Streptococcus dysgalactiae subsp. equisimilis (SDSE) are the beta-hemolytic streptococci species with the most clinical relevance to humans. These species are responsible for several infections, ranging from mild to life-threatening diseases. Although resistance to recommended drugs has not been so critical as detected in other species, it has occurred in diverse regions. In Brazil, it is possible to observe an increasing macrolide and lincosamide resistance trend due to the spread of polyclonal strains. Macrolide-lincosamidestreptogramin B (MLS) resistance phenotypes have been prevalent among S. agalactiae and S. pyogenes, while $\mathrm{M}$ phenotype (resistance only to macrolides) has prevailed among SDSE resistant isolates. Fluoroquinolone resistance is rare in this country, reported only in S. agalactiae and S. pyogenes. This is due to nucleotide substitutions in gyr $A$ and parC genes. Reduced penicillin susceptibility and vancomycin resistance, detected in other regions, have not yet been reported in Brazil. Tetracycline is not a therapeutical option, and resistance has occurred at high levels, especially among S. agalactiae. These findings highlight the need for continuous monitoring in order to track the occurrence of antimicrobial resistance among beta-hemolytic streptococci species circulating in this country.

Keywords: Streptococcus agalactiae; Streptococcus pyogenes; Streptococcus dysgalactiae subsp. equisimilis (SDSE); beta-hemolytic streptococci; antimicrobial resistance; Brazil

\section{Introduction}

Beta-hemolytic streptococci species are important human pathogens, associated with diseases that occur in subjects with different age ranges or health status. Infections are mainly caused by Streptococcus pyogenes (Group A streptococci), Streptococcus agalactiae (Group B streptococci), and less frequently, Streptococcus dysgalactiae subsp. equisimilis, SDSE (Groups C and G streptococci). Streptococcus spp. are members of the human body microbiota, and pathogenic species can colonize asymptomatically, as $S$. pyogenes in the oropharynx or $S$. agalactiae in the genital tract of pregnant women. Infections range from being superficial and mild, such as sore throat and impetigo, to being invasive and life-threatening, such as streptococcal toxic shock syndrome and neonatal meningitis. Immunological complications, rheumatic fever, and acute glomerulonephritis, developed after a streptococcal infection, corroborate the pathogenic burden of such species [1].

Antimicrobial agents are used in virtually all infections due to beta-hemolytic streptococci once diagnosed, regardless of severity, since it reduces symptoms and prevents immunological complications associated with S. pyogenes and SDSE pharyngitis or impetigo. Penicillin remains the first option for therapy of streptococcal pharyngitis and prophylaxis of $S$. agalactiae neonatal infections. Recommended alternatives include cephalosporins, lincosamides, macrolides, and vancomycin [2,3]. Fluoroquinolones are also an alternative therapy, especially for invasive streptococcal infections [4].

Beta-hemolytic streptococci resistance to recommended antimicrobial agents has been reported in recent decades. While resistance to drugs such as macrolides and lincosamides has been detected in several regions, occurring at different rates, resistance to other antimicrobials, such as beta-lactams, has been rarely or recently reported. 
Although uniformly susceptible to penicillin for years, beta-hemolytic streptococci have recently developed resistance to such a drug. Reduced penicillin susceptibility, leading to minimal inhibitory concentration (MIC) of $0.25-1 \mu \mathrm{g} / \mathrm{mL}$ (susceptibility corresponds to MIC of $0.12 \mu \mathrm{g} / \mathrm{mL}$ or lower) was first described in S. agalactiae clinical isolates recovered in 1995-2005 in Japan. DNA sequencing made it possible to observe a few nucleotide substitutions in several penicillin-binding protein (PBP)-encoding genes ( $p b p$ genes). However, only mutations leading to amino acid substitutions in the transpeptidase active site of PBP2x (Q557E and V405A) were associated with reduced susceptibility [5]. Later, SDSE isolates with penicillin MIC of $0.5 \mu \mathrm{g} / \mathrm{mL}$ were reported and related to amino acid substitutions in several PBPs. Once again, alterations in the transpeptidase active site of PBP2x (T341P and Q555E) were linked to penicillin reduced susceptibility [6]. Two clinical isolates of $S$. pyogenes, with higher ampicillin and amoxicillin MICs, were recently reported. Unlike what is observed in the other species, nucleotide substitutions were found only in the $p b p 2 x$ gene, leading to T553K in PBP2x [7].

Macrolide resistance among beta-hemolytic streptococci was first reported in 1959 in S. pyogenes, and since then, two major resistance mechanisms have been described in the three species addressed here. Target modification by ribosomal methylases encoded by erm A and ermB genes confers the macrolide-lincosamide-streptogramin B (MLS) resistance phenotype. The MLS phenotype can be constitutive, when the enzyme is continuously synthesized (cMLS), or inducible, when enzyme synthesis is stimulated by a macrolide (iMLS). The expression of efflux pumps, encoded by the mefA gene, is related to the $\mathrm{M}$ phenotype and confers resistance only to macrolides of 14 and 15 carbon atoms. Macrolide resistance among beta-hemolytic streptococci has been reported in different geographical regions at varied rates [1]. Besides being associated with target modification (MLS phenotypes), resistance to lincosamides may also occur among macrolide susceptible isolates, named the L phenotype. Such a phenotype results from drug inactivation, encoded by the $\ln u B(\operatorname{lin} B)$ gene. Another mechanism, characterized by the efflux of drugs, is encoded by the lsa gene family. This genotype determines resistance to lincosamide, streptogramin A and pleuromutilins. Resistance only to lincosamide is much less frequent than macrolide resistance, and it has been reported among S. agalactiae and S. pyogenes isolates $[1,8]$

Fluoroquinolone resistance among beta-hemolytic streptococci was firstly described in the late 1990s and early 2000s. It is due to nucleotide substitutions in quinolone resistance determinant regions (QRDR) of Gyrase and Topoisomerase IV encoding genes, especially gyrA and parC [9-11]. Among S. agalactiae, the first described amino acid changes that led to resistance to fluoroquinolones were S81L and S79F, due to nucleotide substitutions in gyrA and parC, respectively [9]. Among S. pyogenes, amino acid substitutions in ParC (S79A, F, or Y) were associated with fluoroquinolone resistance [10]. SDSE, as S. agalactiae, has shown nucleotide substitutions in gyrA, leading to S81F, L, Y, or C. Mutations in $\operatorname{parC}$ led to the same substitutions observed among S. pyogenes and also in D83G, N, or Y [11]. Resistance to these antimicrobials has been described in different regions but remains at low levels.

Vancomycin resistance among beta-hemolytic streptococci was reported in two epidemiologically non-related clinical isolates of $S$. agalactiae, recovered in different regions of the USA. Isolates were capsular type II and ST 22 by multilocus sequence typing (MLST). Both isolates had vancomycin MIC of $4 \mu \mathrm{g} / \mathrm{mL}$ (susceptibility corresponds to MIC of $1 \mu \mathrm{g} / \mathrm{mL}$ or lower) and harbored a sequence that shared identity with the Enterococcus faecalis van $G$ element [12]. Table 1 summarizes the most relevant resistance mechanisms to recommended antimicrobials. 
Table 1. Summary of relevant resistance mechanisms to antimicrobial agents recommended to the beta-hemolytic streptococci species addressed in this review.

\begin{tabular}{|c|c|c|c|}
\hline Antimicrobial Agent & Resistance Mechanism & Genotype & Global Prevalence \\
\hline Penicillin & Modified target site & $\begin{array}{l}\text { Nucleotide substitution in } p b p 2 x \\
\text { gene }\end{array}$ & Reported in all species; rare \\
\hline Macrolide & Efflux pump & Presence of $m e f A$ gene & Commonly reported in all \\
\hline & Modified target site & Presence of erm genes & species at varied rates \\
\hline Lincosamide & $\begin{array}{l}\text { Drug inactivation } \\
\text { Efflux pump }\end{array}$ & $\begin{array}{l}\text { Presence of } \ln u B \text { gene } \\
\text { Presence of } l s a \text { gene }\end{array}$ & $\begin{array}{l}\text { Reported in } S . \text { agalactiae and } S . \\
\text { pyogenes; rare }\end{array}$ \\
\hline Fluoroquinolone & Modified target site & $\begin{array}{l}\text { Nucleotide substitution in gyr } A \\
\text { and parC genes }\end{array}$ & $\begin{array}{c}\text { Reported in all species at } \\
\text { varied rates }\end{array}$ \\
\hline Vancomycin & Modified target site & Presence of van $G$ gene & Reported in S. agalactiae; very rare \\
\hline
\end{tabular}

Brazil is the largest country in Latin America, with a projected 213.2 million inhabitants [13]. Social inequalities are historical and strongly impact population access to health assistance and education. The country is divided into five major geographical regions, South and Southeast being the most developed. These two regions have better human development indexes, such as lower infant mortality rates and longer life expectancy, compared to national rates (11.9 per live 1000 births and 76.6 years, respectively) [14]. While some health threats have a national compulsory notification [15], which contributes to their continuous epidemiological surveillance, others, including several infectious diseases, do not have a national notification system. Regional differences can be observed in data production and analysis, with the majority of studies being conducted in the most developed regions cited above. Regarding therapeutical regimens, it is noteworthy that the Brazilian Health Regulatory Agency (Anvisa) has recently made available national data about antibiotic consumption [16], which may be an important tool to evaluate antimicrobial resistance rates among bacterial pathogens circulating in the country.

Infections due to beta-hemolytic streptococci are not nationally reported, and GBS screening among pregnant women at low risk is not recommended by public health authorities in Brazil [17]. Epidemiological data about infections and antimicrobial resistance rates have been generated by researchers mainly affiliated with academic institutions. In this review, I evaluated available data about antimicrobial resistance rates of betahemolytic streptococci species, associated with colonization and infections, that have occurred exclusively in the human population living in this country.

\section{Results}

Twenty-seven published articles about antimicrobial resistance rates of $S$. agalactiae (17), S. pyogenes (7), SDSE (2), and S. pyogenes / SDSE (1) were selected, comprising a period of 17 years (2003-2020). All studies followed Clinical and Laboratory Standards Institute (CLSI) guidelines to perform antimicrobial susceptibility testing (AST) and investigate macrolide resistance phenotypes. The detailed steps for article eligibility are shown in Table 2.

Table 2. Published articles in Lilacs and PubMed databases and selection steps.

\begin{tabular}{|c|c|}
\hline Articles/Selection Step ${ }^{1}$ & Number \\
\hline Articles found using search terms & 150 \\
\hline Duplicated articles * & 72 \\
\hline Abstracts screened & 78 \\
\hline Abstracts rejected * (not human subjects; no data about antimicrobial resistance) & 39 \\
\hline Articles sought for retrieval & 39 \\
\hline Articles not retrieved * & 3 \\
\hline Articles assessed for eligibility & 36 \\
\hline Articles rejected * (lack of macrolide resistance phenotype or genotype investigation) & 9 \\
\hline Eligible articles & 27 \\
\hline
\end{tabular}

${ }^{1}$ Selection steps are highlighted with an asterisk $\left({ }^{*}\right)$. 


\subsection{Streptococcus agalactiae}

S. agalactiae represents the beta-hemolytic streptococci with a greater amount of AST data in Brazil. This may reflect its clinical relevance regarding neonatal infections, although national health authorities have not recommended universal screening. Studies were published in 2003-2020, comprising isolates recovered from 1980 to 2018. Most studies were performed in Rio de Janeiro, a Southeast state, followed by Southern states (Paraná, Santa Catarina, and Rio Grande do Sul). Data from all other regions were also available. The majority of $S$. agalactiae isolates were recovered from pregnant women, but isolates from neonates and non-pregnant adults were also included. Resistance to beta-lactams and vancomycin has not been detected. However, resistant isolates to lincosamides, macrolides, and fluoroquinolones have been reported.

Analysis of clindamycin and erythromycin non-susceptibility rates over the years was performed with data from 15 studies [18-32], divided according to the period (until and after 2010) and locality of isolates recovery (Table 3). Non-susceptibility refers to resistant and intermediate isolates, according to CLSI definitions and breakpoints. Clindamycin nonsusceptibility rates have varied from 1.9 to $18.8 \%$, while erythromycin rates have ranged from 4 to $25 \%$. No statistical difference was observed among resistance rates according to the locality. However, isolates recovered after 2010 were significantly more resistant to both antimicrobials, with mean rates of clindamycin and erythromycin resistance of $6.5 \%$ and $6.8 \%$, respectively, until 2010 , and $11.3 \%$ and $16.2 \%$ after 2010 . MLS phenotypes, as well as erm genes, were prevalent. Two studies $[21,31]$ reported the occurrence of the $\mathrm{L}$ phenotype, but no further genetic characterization of such isolates was available since $\ln u B$ gene investigation failed [21]. Capsular type $\mathrm{V}$ has predominated among macrolide-resistant isolates, followed by types Ia and III.

Table 3. Prevalence and characteristics of erythromycin and clindamycin non-susceptible S. agalactiae recovered in Brazil.

\begin{tabular}{|c|c|c|c|c|c|c|}
\hline $\begin{array}{c}\text { Period of Isolates } \\
\text { Recovery }\end{array}$ & $\begin{array}{c}\text { Locality } \\
\text { (No. of Studies) }\end{array}$ & Cli NS\% & Ery NS\% & Ery Phenotypes ${ }^{1}$ & $\begin{array}{c}\text { Ery } \\
\text { Genotypes } 2\end{array}$ & $\begin{array}{c}\text { Capsular } \\
\text { Types }^{3}\end{array}$ \\
\hline \multirow[t]{3}{*}{ Until 2010} & RJ (5) & $4.3-16.7$ & $4.6-13.2$ & iMLS, cMLS & ermA & $\mathrm{V}, \mathrm{Ia}$ \\
\hline & $\mathrm{BR}^{4}(2)$ & $1.9-3.4$ & 4 & cMLS, M & erm $A$, three 5 & Ia, III \\
\hline & PR (1) & 4.7 & 4.7 & cMLS & ermA/ermB ${ }^{6}$ & II, V \\
\hline \multirow[t]{4}{*}{ After 2010} & $\mathrm{RJ}(3)$ & $3.3-12.2$ & $11.3-14.3$ & iMLS/cMLS 6, M & erm $A$, erm $B$ & V, III, Ia \\
\hline & PR (2) & $8.1-13.3$ & $8.1-19.3$ & iMLS & ermA & $\mathrm{V}$ \\
\hline & RS (1) & 14.2 & 21.4 & M & mefA & NT \\
\hline & BA (1) & 18.8 & 25 & cMLS, $\mathrm{M}$ & ermB/mef 6 & NT \\
\hline
\end{tabular}

No., number; Cli, clindamycin; NS, non-susceptible; Ery, erythromycin; RJ, Rio de Janeiro; PR, Paraná; RS, Rio Grande do Sul; BA, Bahia; NT, not tested. ${ }^{1}$ Prevalent erythromycin-resistant phenotypes in the majority of studies; ${ }^{2}$ prevalent erythromycin-resistant genotypes in the majority of studies; ${ }^{3}$ prevalent capsular types in the majority of studies; ${ }^{4}$ studies conducted in more than one state of Brazil ${ }^{5}{ }^{5}$ three macrolide resistance genes were simultaneously found $(\operatorname{erm} A, \operatorname{ermB}, m e f A) ;{ }^{6}$ simultaneous detection of such phenotype or genotype.

Fluoroquinolone resistance has been a rare event, reported in only three studies since 2011. Resistance rates have varied from 1-7.1\% [20,30,31]. Further comprehensive characterization of the first resistant isolates demonstrated a non-clonal relationship among isolates. Point mutations were detected in QRDR of $g y r A$ and $\operatorname{parC}$ genes, leading to S81L in GyrA and S79F in ParC, both associated with levofloxacin resistance [33].

Although tetracycline has not been recommended for the therapy of any infection due to beta-hemolytic streptococci, testing of such a drug was performed in several studies in order to monitor resistance. Tetracycline resistance rates have varied from $75-100 \%$, as observed in 11 studies $[18-22,26-30,34]$. The mean rate was $87.3 \%$, without any significant differences regarding the period or locality of isolates' recovery. Genetic determinants of tetracycline resistance were investigated in two studies, being tet $M$ the most frequent, followed by tet $O$ and tet $L[19,26]$. These genotypes are associated with modified target sites (tet $M$ and tetO) and efflux pump expression (tet $L$ ). 


\subsection{Streptococcus pyogenes}

Although several papers about the epidemiology of S. pyogenes infections have been published, only seven studies that reported AST in isolates circulating in Brazil were eligible for this review. As observed in S. agalactiae, most studies were conducted in Rio de Janeiro. Data from São Paulo (Southeast), the Federal District (Central-West region), and Southern states were also available. Studies were published in 2003-2019 and comprised isolates recovered over 24 years (1993-2017). Regarding clinical origin, most isolates were obtained from oropharynx secretion, followed by skin and sterile site specimens.

Reduced penicillin susceptibility has not been reported among S. pyogenes isolates. On the other hand, clindamycin and erythromycin non-susceptibility rates have varied from 0.8 to $15.4 \%$ (mean $5.5 . \%$ ) and from 1.6 to $15.4 \%$ (mean $5.9 \%$ ), respectively. Although the $\mathrm{M}$ phenotype and $m e f A$ gene have been predominant in earlier studies, the MLS phenotypes, associated with $\mathrm{erm}$ genes, became prevalent among macrolide-resistant $S$. pyogenes isolates after 2000 [35-39]. Several emm types have been detected among resistant isolates, such as $11,12,22,58,73$, and $78[37,38]$. No reports of clindamycin resistance associated with the L phenotype have been found.

Non-susceptibility to fluoroquinolones was reported only in one study, published in 2009 [40]. Eight isolates, $6.1 \%$ of a sampling of 130 S. pyogenes submitted to AST, presented ciprofloxacin MIC of $2 \mu \mathrm{g} / \mathrm{mL}$ (neither CLSI nor EUCAST have defined breakpoints to this antimicrobial). Isolates showed a polyclonal origin, belonging to several emm types, such as 59, 6, and 74. Amino acid substitutions (S79A or F) were found in ParC [40].

Tetracycline resistance has varied from 13.6 to $61 \%$, with a mean rate of $31.8 \%$ [35-39,41]. The highest rate was obtained in a study from the Federal District, with isolates recovered in 2004 [41]. Over time, a decreasing trend has been observed, with the lowest rates detected in most recent studies $[38,39]$. Only the tet $M$ genetic determinant was found among tetracycline-resistant isolates, as reported by one study [41].

\subsection{Streptococcus dysgalactiae subsp. equisimilis}

Groups C and G streptococci have been at the center of taxonomic changes in recent decades, being groups $\mathrm{C}$ and $\mathrm{G}$ with large and beta-hemolytic colonies, recovered from humans, designated as Streptococcus dysgalactiae subsp. equisimilis [42]. SDSE has a high genetic relatedness with $S$. pyogenes, sharing several virulence factors and causing similar clinical manifestations. In this review, only three studies were eligible, being published in 2015-2019. Most of the bacterial isolates were recovered from oropharynx secretion, from 1979 to 2017, in Rio de Janeiro and São Paulo.

As observed in the other species, reduced penicillin susceptibility has not been detected among SDSE isolates circulating in Brazil. Clindamycin and erythromycin nonsusceptibility rates have varied from 6.8 to $23.1 \%$ (mean $13.4 \%$ ) and from 13.9 to $30.8 \%$ (mean 21\%), respectively. The M phenotype and mefA gene were predominant, followed by iMLS phenotype and ermA gene $[39,43,44]$. Several emm types have been associated with macrolide resistance, such as stG840.0, stG653.0, stC36.0 and stC1400.0 [39,44].

Fluoroquinolone resistance has not been reported among SDSE circulating in Brazil. On the other hand, the tetracycline resistance mean rate was 37.2\% [39,43,44]. As observed in S. pyogenes, a decreasing trend has been detected over time. Rates varied from $65.2 \%$ in a study with isolates recovered from 1979 to 2008 [43] to $7.7 \%$ in the latest study, whose isolates were recovered from 2015 to 2017 [39]. Both tetK and tet $M$ genes were found in tetracycline-resistant isolates [43].

\section{Discussion}

Antimicrobial resistance is a global health concern with a high burden, especially to some human pathogens, such as the ESKAPE group [45]. Streptococcus pneumoniae is the species with the most substantial impact among the streptococci due to the relevant prevalence of invasive pneumococcal infections, such as pneumonia and meningitis, and its resistance to beta-lactams, macrolides, fluoroquinolones, and other antimicrobials [46]. 
Beta-hemolytic streptococci encompass several human pathogens associated with morbidity and mortality in newborns, children, and adult populations. Although resistance rates to recommended drugs are not as high as in other species, it should also be viewed with concern [46].

As mentioned before, in Brazil, there is neither notification of streptococcal infections nor a recommendation of $S$. agalactiae universal screening among pregnant women [17]. Furthermore, national statistics on antimicrobial resistance rates do not exist. Only very recently, Anvisa has made data available about antimicrobial consumption [16]. However, there is still a lack of information about how frequent antimicrobials have been consumed to treat streptococcal infections in the country.

Reduced penicillin susceptibility has not been reported in Brazil. However, it is essential to highlight that such resistance can only be detected when MIC testing is performed or a specific combination of antimicrobials in disk diffusion testing is used [47].

Resistance to recommended therapeutical alternatives, such as macrolides and lincosamides, has been detected in several studies. Among S. agalactiae, increasing resistance, as observed in later studies, is significant. These reports have shown the prevalence of MLS phenotypes and erm genotypes, which also confer resistance to clindamycin, one recommended alternative therapy to prevent neonatal infection [3]. Studies performed in other regions have also observed an increasing resistance trend, with the prevalence of MLS phenotypes, as reported in Portugal [48].

Macrolide resistance among $S$. pyogenes isolates has been frequently reported over time, and a change in resistance phenotypes and genotypes prevalence is evident. The $M$ phenotype, predominant in earlier studies, has lately been replaced by MLS phenotypes. As a consequence of such changes, higher rates of clindamycin resistance have been observed in these later studies. MLS phenotypes have also been prevalent in recent studies conducted in other countries, such as in Greece [49]. Among SDSE isolates, despite the low amount of data available, it was possible to observe that resistance to macrolides and lincosamides has occurred over time. The $M$ phenotype and mef $A / E$ genotype have prevailed among such isolates.

A matter of concern is the recent and widespread usage of azithromycin for "early treatment" of COVID-19 patients in Brazil, as controversially recommended by national health authorities [50]. Considering that streptococci resistance to macrolides has been linked to the consumption of these agents [51], monitoring macrolide resistance in the following years will be critical to verify drug efficacy.

There are few reports of fluoroquinolone resistance among beta-hemolytic streptococci circulating in Brazil, occurring among S. pyogenes and S. agalactiae. Genetic characterization of resistant isolates, performed in only two studies $[33,40]$, detected nucleotide substitutions in gyr $A$ and parC genes, as described in studies conducted in other geographical regions.

Tetracycline has been recommended neither to prevent nor to treat infections due to beta-hemolytic streptococci [2,3]. Similarly, CLSI does not include tetracycline in the list of drugs to be tested and reported when AST is performed. However, testing of such antimicrobial has been performed in several studies conducted in Brazil in order to track streptococcal resistance. According to available data, it is possible to observe two patterns over time. While $S$. agalactiae remains broadly resistant, reduced rates have been detected among $S$. pyogenes and SDSE isolates in recent studies. Lower resistance rates in these later species may be associated with lesser consumption of tetracycline by Brazilian inhabitants since this antimicrobial is neither a recommended therapy nor can be sold without a prescription, according to a 2011 Anvisa resolution [52]. On the other hand, tetracycline is one of the most relevant antimicrobials used in veterinary settings, where S. agalactiae is also an important pathogen, significantly associated with bovine mastitis [53]. Unlike human antibiotic consumption, in Brazil, there is no antibiotic sale control for animal usage.

As one can see, data about antimicrobial resistance in beta-hemolytic streptococci in Brazil are modest. AST's massive performance must be encouraged in health care settings, followed by notification of unusual resistance phenotypes to reference or research 
laboratories. This is essential to track antimicrobial resistance and investigate phenotypic and genotypic characteristics of resistant isolates. The generation of national data is vital to improve knowledge about streptococcal infection prevalence and improving therapeutical practices in this population.

\section{Materials and Methods}

Search Terms and Selection Criteria: This review aimed to search and analyze data about antimicrobial resistance rates of beta-hemolytic streptococci associated with colonization and infection in the human population living in Brazil. The analysis included macrolide-resistant phenotypes and genotypes and epidemiological markers of resistant isolates (capsular types of S. agalactiae and emm types of S. pyogenes and SDSE). Searching was carried out in PubMed and Lilacs Databases, regardless of the year of publication. Generic search terms were: Streptococcus agalactiae AND antimicrobial resistance AND Brazil; Group B streptococcus AND antimicrobial resistance AND Brazil; Streptococcus pyogenes AND antimicrobial resistance AND Brazil; Group A streptococcus AND antimicrobial resistance AND Brazil; Streptococcus dysgalactiae subsp. equisimilis AND antimicrobial resistance AND Brazil.

Inclusion criteria: original articles or case reports that provided data about AST, performed according to standard guidelines, of S. agalactiae, S. pyogenes, and SDSE isolates recovered from humans.

Exclusion criteria: studies involving beta-hemolytic streptococci recovered from animals; studies that have not performed phenotypic or genotypic macrolide resistance investigation when erythromycin resistance has been detected. Selection steps are shown in Table 2.

Data of eligible articles were summarized in an Excel sheet. Mean rates were calculated. Statistical analysis, ANOVA (https:/ / goodcalculators.com/one-way-anova-calculator/, accessed on 8 June 2021), and Student $t$-test (https: / / www.graphpad.com/quickcalcs / ttest1/, accessed on 8 June 2021) were performed to check statistical significance in $S$. agalactiae data.

\section{Conclusions}

This study brings a comprehensive view of antimicrobial resistance among betahemolytic streptococci circulating in Brazil. There is no national notification system in this country to monitor streptococcal infection prevalence and antimicrobial resistance rates. However, it is possible to observe that macrolide and lincosamide resistance occurs among all relevant species, which demands a continuous survey. This becomes especially critical with the recent and controversial usage of azithromycin to treat COVID-19. Reliable AST methods must be used in order to detect reduced penicillin susceptibility, the firstline regimen for therapy and prevention of streptococcal infections, which may demand training of personnel and additional costs. In addition, fluoroquinolone and vancomycin resistance surveillance is also important since both drugs are also reliable options for streptococcal infections. Tetracycline resistance occurs at high levels in S. agalactiae while having decreased S. pyogenes and SDSE. A better communication among clinical and reference laboratories is also imperative in order to generate robust data about antimicrobial resistance and, therefore, to guide therapeutical strategies in the country.

Funding: This study received no external funding.

Acknowledgments: The author thanks Geraldo Renato de Paula, from Universidade Federal Fluminense, for critical reading of the manuscript draft.

Conflicts of Interest: The author declares no conflict of interest.

\section{References}

1. Haenni, M.; Lupo, A.; Madec, J.Y. Antimicrobial resistance in Streptococcus spp. Microbiol. Spectr. 2018, 6. [CrossRef] 
2. Schulman, S.T.; Bisno, A.L.; Clegg, H.W.; Gerber, M.A.; Kaplan, E.L.; Lee, G.; Martin, J.M.; Beneden, C.M. Clinical practice guidelines for the diagnosis and management of group A streptococcal pharyngitis: 2012 update by the Infectious Disease Society of America. Clin. Infect. Dis. 2012, 55, 1279-1282. [CrossRef] [PubMed]

3. ACOG Committee Opinion. Prevention of group B streptococcal early-onset disease in newborns. Obstet. Gynecol. 2020, 135, e51-e72. [CrossRef] [PubMed]

4. Arensman, K.; Shields, M.; Beganovic, M.; Miller, J.L.; LaChance, E.; Anderson, M.; Dela-Pena, J. Fluoroquinolone versus beta-lactam oral step-down therapy for uncomplicated streptococcal bloodstream infections. Antimicrob. Agents Chemother. 2020, 64, e01515-20. [CrossRef]

5. Kimura, K.; Suzuki, S.; Wachino, J.; Kurokawa, H.; Yamane, K.; Shibata, N.; Nagano, N.; Kato, H.; Shibayama, K.; Arakawa, Y. First molecular characterization of group B streptococci with reduced penicillin susceptibility. Antimicrob. Agents Chemother. 2008, 52, 2890-2897. [CrossRef]

6. $\quad$ Fuursted, K.; Stegger, M.; Hoffmann, S.; Lambertsen, L.; Andersen, P.S.; Deleuran, M.; Thomsen, M.K. Description and characterization of a penicillin-resistant Streptococcus dysgalactiae subsp. equisimilis clone isolated from blood in three epidemiologically linked patients. J. Antimicrobiol. Chemother. 2016, 71, 3376-3380.

7. Vannice, K.S.; Ricaldi, J.; Nanduri, S.; Fang, F.C.; Lynch, J.B.; Bryson-Cahn, C.; Wright, T.; Duchin, J.; Kay, M.; Chochua, S.; et al. Streptococcus pyogenes pbp2x mutation confers reduced susceptibility to $\beta$-lactam antibiotics. Clin. Infect. Dis. 2020, 71, 201-204. [CrossRef] [PubMed]

8. Berbel, D.; Càmara, J.; García, E.; Tubau, F.; Guérin, F.; Giard, J.F.; Domínguez, M.A.; Cattoir, V.; Ardanuy, C. A novel genomic island harbouring $l_{s} a(\mathrm{E})$ and $\ln u(\mathrm{~B})$ genes and a defective prophage in a Streptococcus pyogenes isolate resistant to lincosamide, streptogramin A and pleuromutilin antibiotics. Intern. J. Antimicrob. Agents 2019, 54, 647-651. [CrossRef] [PubMed]

9. Kawamura, Y.; Fujiwara, H.; Mishima, N.; Tanaka, Y.; Tanimoto, A.; Ikawa, S.; Itoh, Y.; Ezaki, T. First Streptococcus agalactiae isolates highly resistant to quinolones with point mutations in gyr A and par C. Antimicrob. Agents Chemother. 2003, 47, 3605-3609. [CrossRef] [PubMed]

10. Malhotra-Kumar, S.; Lammens, C.; Chapele, S.; Mallentjer, C.; Weyler, J.; Goossens, H. Clonal spread of fluoroquinolone non-susceptible Streptococcus pyogenes. J. Antimicrobiol. Chemother. 2005, 55, 320-325. [CrossRef]

11. Biedenbach, D.J.; Toleman, M.A.; Walsh, T.R.; Jones, R.N. Characterization of fluoroquinolone-resistant h-hemolytic Streptococcus spp. isolated in North America and Europe including the first report of fluoroquinolone-resistant Streptococcus dysgalactiae subspecies equisimilis: Report from the SENTRY Antimicrobial Surveillance Program (1997-2004). Diagn. Microbiol. Infect. Dis. 2006, 55, 119-127.

12. Park, C.; Nichols, M.; Schrag, S. Two cases of invasive vancomycin-resistant group B streptococcus infection. N. Engl. J. Med. 2014, 370, 885-886. [CrossRef]

13. Instituto Brasileiro de Geografia e Estatística. Available online: https://www.ibge.gov.br/apps/populacao/projecao/index.html (accessed on 14 June 2021).

14. Instituto Brasileiro de Geografia e Estatística. Tábua Completa de Mortalidade Para o Brasil 2019; IBGE: Rio de Janeiro, Brazil, 2020; pp. 6-13.

15. Ministério da Saúde do Brasil. Available online: https://bvsms.saude.gov.br/bvs/saudelegis/gm/2020/prt0264_19_02_2020 .html (accessed on 18 May 2021).

16. Agência Nacional de Vigilância Sanitária-Anvisa. Available online: https:/ /www.gov.br/ptbr/servicos/consultar-dados-devendas-de-medicamentos-controlados-antimicrobianos-e-outros (accessed on 24 May 2021).

17. Ministério da Saúde do Brasil. Atenção Ao Pré-Natal de Baixo Risco, 1st ed.; Ministério da Saúde: Brasília, Brazil, 2013; pp. 193-194.

18. D'Oliveira, R.E.C.; Barros, R.R.; Mendonça, C.R.V.; Teixeira, L.M.; Castro, A.C.D. Susceptibility to antimicrobials and mechanisms of erythromycin resistance in clinical isolates of Streptococcus agalactiae from Rio de Janeiro, Brazil. J. Med. Microbiol. 2003, 52, 1029-1030. [CrossRef]

19. Duarte, R.S.; Bellei, B.C.; Miranda, O.P.; Brito, M.A.V.P.; Teixeira, L.M. Distribution of antimicrobial resistance and virulencerelated genes among Brazilian Group B Streptococci recovered from bovine and human sources. Antimicrob. Agents Chemother. 2005, 49, 97-103. [CrossRef]

20. Nakamura, P.A.; Schuab, R.B.; Neves, F.P.; Pereira, C.F.; Paula, G.R.; Barros, R.R. Antimicrobial resistance profiles and genetic characterisation of macrolide resistant isolates of Streptococcus agalactiae. Mem. Inst. Oswaldo Cruz 2011, 106, 119-122. [CrossRef] [PubMed]

21. Correa, A.B.; Silva, L.G.; Pinto, T.C.A.; Oliveira, I.C.; Fernandes, F.G.; Costa, N.S.; Mattos, M.C.; Fracalanzza, S.E.L.; Benchetrit, L.C. The genetic diversity and phenotypic characterisation of Streptococcus agalactiae isolates from Rio de Janeiro, Brazil. Mem. Inst. Oswaldo Cruz 2011, 106, 1002-1006. [CrossRef]

22. Souza, V.C.; Kegele, F.O.C.; Souza, S.R.; Neves, F.P.G.; Paula, G.R.; Barros, R.R. Antimicrobial susceptibility and genetic diversity of Streptococcus agalactiae recovered from newborns and pregnant women in Brazil. Scand. J. Infect. Dis. 2013, 45, 780-785. [CrossRef] [PubMed]

23. Palmeiro, J.K.; Dalla-Costa, L.M.; Fracalanzza, S.E.L.; Botelho, A.C.N.; Nogueira, K.S.; Scheffer, M.C.; Torres, R.S.L.A.; Carvalho, N.S.; Cogo, L.L.; Madeira, H.M.F. Phenotypic and genotypic characterization of group B streptococcal isolates in Southern Brazil. J. Clin. Microbiol. 2010, 48, 4397-4408. [CrossRef] [PubMed] 
24. Otaguiri, E.S.; Morguette, A.E.; Tavares, E.R.; Santos, P.M.; Morey, A.T.; Cardoso, J.D.; Perugini, M.R.E.; Yamauchi, L.M.; Yamada-Ogatta, S.F. Commensal Streptococcus agalactiae isolated from patients seen at University Hospital of Londrina, Parana, Brazil: Capsular types, genotyping, antimicrobial susceptibility and virulence determinants. BMC Microbiol. 2013, 13, 297. [CrossRef]

25. Barros, R.R.; Souza, A.F.; Luiz, F.B.O. Polyclonal spread of Streptococcus agalactiae resistant to clindamycin among pregnant women in Brazil. J. Antimicrob. Chemother. 2016, 71, 2054-2056. [CrossRef]

26. Dutra, V.G.; Alves, V.M.N.; Olendzki, A.N.; Dias, C.A.G.; Bastos, A.F.A.; Santos, G.O.; Amorim, E.L.; Sousa, M.A.; Santos, R.; Ribeiro, P.C.; et al. Streptococcus agalactiae in Brazil: Serotype distribution, virulence determinants and antimicrobial susceptibility. BMC Infect. Dis. 2014, 14, 323. [CrossRef] [PubMed]

27. Schuab, R.B.B.; Arêas, G.P.; Souza, V.C.; Barros, R.R. Molecular epidemiology of Streptococcus agalactiae recovered from significant bacteriuria. Infect. Dis. 2015, 47, 637-642. [CrossRef]

28. Melo, S.C.C.S.; Santos, N.C.S.; Oliveira, M.; Scodro, R.B.L.; Cardoso, R.F.; Pádua, R.A.F.; Silva, F.T.R.; Costa, A.B.; Carvalho, M.D.B.; Pelloso, S.M. Antimicrobial susceptibility of Streptococcus agalactiae isolated from pregnant women. Rev. Inst. Med. Trop. São Paulo 2016, 58, 83. [CrossRef] [PubMed]

29. Pinto, T.C.A.; Costa, N.S.; Souza, A.R.V.; Silva, L.G.; Correa, A.B.A.; Fernandes, F.G.; Oliveira, I.C.M.; Mattos, M.C.; Rosado, A.S.; Benchetrit, L.C. Distribution of serotypes and evaluation of antimicrobial susceptibility among human and bovine Streptococcus agalactiae strains isolated in Brazil between 1980 and 2006. Braz. J. Infect. Dis. 2013, 17, 131-136. [PubMed]

30. Botelho, A.C.N.; Oliveira, J.G.; Damasco, A.P.; Santos, K.T.; Ferreira, A.F.M.; Rocha, G.T.; Marinho, P.S.; Bornia, R.B.G.; Pinto, T.C.A.; Américo, M.A.; et al. Streptococcus agalactiae carriage among pregnant women living in Rio de Janeiro, Brazil, over a period of eight years. PLoS ONE 2018, 13, e0196925. [CrossRef] [PubMed]

31. Battistin, F.R.; Mott, M.P.; Dias, C.A.G.; Perez, V.P. Suscetibilidade antimicrobiana de Streptococcus agalactiae isolados de gestantes em um hospital materno infantil de Porto Alegre, Rio Grande do Sul. Sci. Med. 2018, 28, ID30246. [CrossRef]

32. Santana, F.A.F.; Oliveira, T.V.L.; Souza-Filho, M.B.; Silva, L.S.C.; Brito, B.B.; Melo, F.F.; Souza, C.L.; Marques, L.M.; Oliveira, M.V. Streptococcus agalactiae: Identification methods, antimicrobial susceptibility, and resistance genes in pregnant women. World $\mathrm{J}$. Clin. Cases. 2020, 8, 3988-3998. [CrossRef] [PubMed]

33. Barros, R.R.; Kegele, F.C.O.; Paula, G.R.; Brito, M.A.; Duarte, R.S. Molecular characterization of the first fluoroquinolone resistant strains of Streptococcus agalactiae isolated in Brazil. Braz. J. Infect. Dis. 2012, 16, 476-478. [CrossRef]

34. Barros, R.R.; Jobst, R.M.S.; Souza, A.F.; Melo, A.L.; Mondino, S.S.B. Avaliação da colonização por Streptococcus agalactiae em gestantes de alto risco atendidas em Niterói-RJ, Brasil. Rev. Patol. Trop. 2015, 44, 386-394. [CrossRef]

35. D'Oliveira, R.E.C.; Barros, R.R.; Mendonça, C.R.V.; Teixeira, L.M.; Castro, A.C.D. Antimicrobial susceptibility and survey of macrolide resistance mechanisms among Streptococcus pyogenes isolated in Rio de Janeiro, Brazil. Microb. Drug Resist. 2003, 9, 87-91. [CrossRef]

36. Mendes, C.; Marin, M.E.; Quiñones, F.; Sifuentes-Osornio, J.; Siller, C.C.; Castanheira, M.; Zoccoli, C.M.; López, H.; Súcari, A.; Rossi, F.; et al. antibacterial resistance of community-acquired respiratory tract pathogens recovered from patients in Latin America: Results from the PROTEKT surveillance study (1999-2000). Braz. J. Infect. Dis. 2003, 7, 44-61. [CrossRef] [PubMed]

37. Torres, R.S.L.A.; Torres, R.P.A.; Smeesters, P.R.; Palmeiro, J.K.; Messias-Reason, I.J.; Dalla-Costa, L.M. Group A Streptococcus Antibiotic Resistance in Southern Brazil: A 17-Year Surveillance Study. Microb. Drug Resist. 2011, 17, 313-319. [CrossRef] [PubMed]

38. Arêas, G.P.; Schuab, R.B.; Neves, F.P.; Barros, R.R. Antimicrobial susceptibility patterns, emm type distribution and genetic diversity of Streptococcus pyogenes recovered in Brazil. Mem. Inst. Oswaldo Cruz 2014, 109, 935-939. [CrossRef]

39. Luiz, F.B.O.; Alves, K.B.; Barros, R.R. Prevalence and long-term persistence of beta- haemolytic streptococci throat carriage among children and young adults. J. Med. Microbiol. 2019, 68, 1526-1533. [CrossRef] [PubMed]

40. Smeesters, P.R.; Vergison, A.; Campos Jr, D.; Van Malderen, L. Emerging fluoroquinolone-non-susceptible group A streptococci in two different paediatric populations. Intern. J. Antimicrob. Agents 2009, 34, 44-49. [CrossRef] [PubMed]

41. Smeesters, P.R.; Cadar, S.; Drèze, P.A.; Campos Jr, D.; Van Malderen, L. Polyclonal dissemination of tetracycline resistance among Streptococcus pyogenes paediatric isolates from Brazil. J Infect Dev Ctries. 2010, 4, 704-711. [CrossRef] [PubMed]

42. Vandamme, P.; Pot, B.; Falsen, E.; Kersters, K.; Devriese, L.A. Taxonomic study of Lancefield Streptococcal groups C, G and L (Streptococcus dysgalactiae) and proposal of S. dysgalactiae subsp. equisimilis subsp. nov. Int. J. Syst. Bacteriol. 1996, 46, 774-781. [CrossRef]

43. Silva, L.G.; Genteluci, G.L.; Mattos, M.C.; Glatthardt, T.; Figueiredo, A.M.S.; Ferreira-Carvalho, B.T. Group C Streptococcus dysgalactiae subsp. equisimilis in south-east Brazil: Genetic diversity, resistance profile and the first report of human and equine isolates belonging to the same multilocus sequence typing lineage. J. Med. Microbiol. 2015, 64, 551-558. [CrossRef]

44. Souza, J.P.; Santos, A.R.; Paula, G.R.; Barros, R.R. Antimicrobial susceptibility and genetic relationship among Streptococcus dysgalactiae subsp equismilis isolates in Rio de Janeiro. Infect. Dis. 2016, 48, 676-681. [CrossRef]

45. De Oliveira, D.M.P.; Forde, B.M.; Kidd, T.J.; Harris, P.N.A.; Schembri, M.A.; Beatson, S.A.; Paterson, D.L.; Walker, M.J. Antimicrobial Resistance in ESKAPE Pathogens. Clin. Microbiol. Rev. 2020, 33, e00181-19. [CrossRef]

46. Centers for Disease Control and Prevention. Antibiotic Resistance Threats in the United States, 2019; U.S. Department of Health and Human Services, CDC: Atlanta, GA, USA, 2019. 
47. Kimura, K.; Wachino, J.; Kurokawa, H.; Suzuki, S.; Yamane, K.; Shibata, N.; Arakawa, Y. Practical disk diffusion test for detecting group B Streptococcus with reduced penicillin susceptibility. J. Clin. Microbiol. 2009, 47, 4154-4157. [CrossRef] [PubMed]

48. Lopes, E.; Fernandes, T.; Machado, M.P.; Carriço, J.A.; Melo-Cristino, J.; Ramirez, M.; Martins, E.R. The Portuguese Group for the Study of Streptococcal Infections. Increasing macrolide resistance among Streptococcus agalactiae causing invasive disease in non-pregnant adults was driven by a single capsular-transformed lineage, Portugal, 2009 to 2015. Eurosurveillance 2018, 23, 1700473. [CrossRef] [PubMed]

49. Grivea, I.N.; Syrogiannopoulos, G.A.; Michoula, A.N.; Gazeti, G.; Malli, E.; Tsilipounidaki, K.; Fouzas, S.; Anthracopoulos, M.B.; Petinaki, E. emm Types and clusters and macrolide resistance of pediatric group A streptococcal isolates in Central Greece during 2011-2017. PLoS ONE 2020, 15, e0232777. [CrossRef] [PubMed]

50. Ministério da Saúde do Brasil. NOTA INFORMATIVA No 9/2020-SE/GAB/SE/MS. Available online: https:/ / portalarquivos. saude.gov.br/images/pdf/2020/May/21/Nota-informativa---Orienta----es-para-manuseio-medicamentoso-precoce-depacientes-com-diagn--stico-da-COVID-19.pdf (accessed on 1 June 2021).

51. Seppala, H.; Klaukka, T.; Vuoppio-Varkila, J.; Muotiala, A.; Helenius, H.; Lager, K.; Huovinen, P. and the Finnish study group for antimicrobial resistance. The effect of changes in the consumption of macrolide antibiotics on erythromycin resistance in group A streptococci In Finland. N. Engl. J. Med. 1997, 337, 441-446. [CrossRef] [PubMed]

52. Agência Nacional de Vigilância Sanitária-Anvisa. Available online: https://bvsms.saude.gov.br/bvs/saudelegis/anvisa/2011 /rdc0020_05_05_2011.html (accessed on 1 June 2021).

53. Cheng, W.N.; Han, S.G. Bovine mastitis: Risk factors, therapeutic strategies, and alternative treatments-A review. Asian-Australas. J. Anim. Sci. 2020, 33, 1699-1713. [CrossRef] [PubMed] 